\title{
Addendum
}

\section{Quantization and the Uniqueness of Invariant Structures}

\author{
William Arveson \\ Department of Mathematics, University of California, Berkeley, CA 94720, USA \\ Commun. Math. Phys. 89, 77-102 (1983)
}

\begin{abstract}
After my paper [1] had gone to press, it was brought to my attention that there exist several papers in the literature which contain statements of results that are equivalent to, or are related to, some of the results proved in [1]. Since I was previously unaware of these articles, no reference to them was made in [1]. This addendum contains a list of the relevant articles, and is intended as a supplement to the bibliography of [1].
\end{abstract}

\section{References}

1. Arveson, W.: Quantization and the uniqueness of invariant structures. Commun. Math. Phys. 89, 77-102 (1983)

2. Gutt, S.: Déformations formelles de l'algèbre des fonctions différentiables sur une variété symplectique. Doctoral thesis, Universite Libre de Bruxelles, academic year 1979-1980

3. Gutt, S.: Contribution à l'étude des espaces symplectiques homogènes. Acad. R. Belg. 44, Fasc. 6 (1983)

4. Bayen, F., Flato, M., Fronsdal, C., Lichnerowicz, A., Sternheimer, D.: Deformation theory and quantization. I. Deformations of symplectic structures. Ann. Phys, 111, 61 (1978)

5. Sternheimer, D.: Deformation theory applied to quantization and group representations. In: Berlin, Heidelberg, New York: Springer

5. Sternheimer, D.: Deformation theory applied to quantization and group representations. In: Lecture Notes in Physics, Vol. 153, pp. 314-318. Berlin, Heidelberg, New York: Springer 1982

Communicated by B. Simon

Received October 8, 1983 